\title{
A COMPARATIVE STUDY OF THERMO-MECHANICAL FATIGUE OF TWO NI-BASED SINGLE CRYSTAL SUPERALLOYS
}

\author{
H. Zhou, M. Osawa, H. Harda, T. Yokokawa, Y. Koizumi, T. Kobayashi, M.Waki, Y. Ro, and I. Okada* \\ High Temperature Mterials 21 Project, National Institute of Materials Science (NIMS), \\ 1-2-1 Sengen, Tsukuba Science City, 305-0047, Japan \\ * Takasago R\&D Center, Mitsubishi Heavy Industries, LTD., Takasago Hyougo 676-8686, Japan
}

Keywords: Thermo-mechanical fatigue, Ni-based superalloy, single-crystal.

\begin{abstract}
The properties of thermo-mechanical fatigue (TMF) of two Ni-base single-crystal (SC) superalloys developed at NIMS were studied. The superalloys with different $\mathrm{Re}$ amounts of $5 \%$ (TMS-75) and 2.4\% (TMS-82+) showed different TMF behaviors. The cycles to failure for both alloys decreased drastically with the increase of hold time $\left(t_{H}\right)$. The TMS-75 showed a longer life than that of the TMS- $82+$ at $t_{\mathrm{H}}=0$. While, the TMS- $82+$ showed a longer life than that of the TMS-75 at $t_{\mathrm{H}} \neq 0$, which would be attributed to the higher tensile strength at $400{ }^{\circ} \mathrm{C}$ and higher stress relaxation resistance at $900{ }^{\circ} \mathrm{C}$ in the TMS-82+. From microstructural studies, some differences were observed between the two alloys in slip bands, and a little rafted $\gamma / \gamma^{\prime}$ structure parallel to the loading stress axis was observed in the TMS-82+ for TMF with a hold time. Transmission electron microscopy (TEM) studies on the stacking faults confirmed the previous results. This work indicates that the TMS- $82+$ could be used satisfactorily in gas turbine engines under some specific condition.
\end{abstract}

\section{Introduction}

Because singe-crystal superalloys offer improved creep and fatigue resistance compared to conventionally cast superalloys, such as equiaxed and directionally solidified columnar grain components, single crystal superalloys have been developed since the early 1990's. For example, TMS-82+ and TMS-75 were developed at NIMS as a modified second- and a third-generation SC superalloys [1-4]. TMS-82+ is of high phase stability and excellent high temperature creep strength. Blades made of these two superalloys were tested in a gas turbine unit a few years ago at Toshiba LTD. in Japan; the tests consisted of approximately 500 hours of practical operation [1].

Thermal-mechanical fatigue is a critical property for applications of high temperature materials [2-6]. For example, the electric power consumption is usually increased from the morning experiencing a peak and decreased in the evening. Hence, under this specific condition gas turbine engines must be started and shutdown once a day to adjust the consumption of electricity energy. The stresses may arise from temperature gradients in the airfoils during startup and shutdown operations or from gradients within the cooled airfoils. Such cyclic loading is referred to as thermo-mechanical fatigue (TMF) [2-4]. During the hold period of operation, blades and vans are subject to compressive stress. It is important to understand the behavior of superalloy during the TMF cycle and the hold time. Designing superalloys of various chemical compositions is one way to achieve these objectives. Nevertheless, the current knowledge regarding TMF failure and the means improving TMF properties by designing new superalloys is limited. The current study compares the TMF behaviors of two SC superalloys (TMS-75 and TMS-82+) by changing their chemical composition. 


\section{Experimental Procedure}

The compositions of the two superalloys, TMS-75 and TMS-82+, superalloy and TMS-82+ is a typical second-generation type. are listed in Table I. TMS-75 is a typical third-generation SC

Table I. Chemical compositions of TMS-75 and TMS-82+ superalloys (in wt.\%).

\begin{tabular}{|l|l|l|l|l|l|l|l|l|l|l|}
\hline & Co & Cr & Mo & W & Al & Ti & Ta & Hf & Re & Ni \\
\hline TMS-75 & 12.0 & 3.0 & 2.0 & 6.00 & 6.00 & - & 6.00 & 0.1 & 5.0 & Balance \\
\hline TMS-82+ & 7.8 & 4.9 & 1.9 & 8.7 & 5.3 & 0.5 & 6.0 & 0.1 & 2.4 & Balance \\
\hline
\end{tabular}

The superalloys were cast at NIMS to SC bars and heat-treated as follows: TMS-75 was solution-treated in argon at $1320{ }^{\circ} \mathrm{C}$ for $8 \mathrm{~h}$, air quenched, aged in argon at $1150{ }^{\circ} \mathrm{C}$ for $4 \mathrm{~h}$, and finally aged at $870{ }^{\circ} \mathrm{C}$ for $20 \mathrm{~h}$. TMS- $82+$ was solution-treated in argon at $1320^{\circ} \mathrm{C}$ for $5 \mathrm{~h}$, air quenched, aged in argon at $1150{ }^{\circ} \mathrm{C}$ for $4 \mathrm{~h}$, and finally aged at $870{ }^{\circ} \mathrm{C}$ for $20 \mathrm{~h}$. A commercial superalloy CMSX-4 and two modified TMS-82+ superalloys were utilized in this study in comparison with the TMS-75 and the TMS-82+.

The microstructure of the heat-treated TMS-75 and TMS- $82+$ bars consisted of about $60 \mathrm{vol} . \%$ of cuboidal $\gamma^{\prime}$ precipitates. The size of the $\gamma^{\prime}$ precipitates was about $0.4 \mu \mathrm{m}$ for both superalloys. Specimens with [001] orientation were machined parallel to the longitudinal direction of the bars for the TMF test. The parallel part of the specimens was $5 \mathrm{~mm}$ in diameter and $15 \mathrm{~mm}$ in length. Deviations from the $<001>$ orientation to the specimen axis were within 7 to $8^{\circ}$.

TMF tests were conducted on a servo-hydraulic, closed-loop machine (MTS-type 810) using radio frequency induction heating system in air. The total strain $\left(\varepsilon_{\mathrm{t}}\right)$ was measured using an axial extensometer on the gauge length of $12 \mathrm{~mm}$. TMF behavior was recorded for simplified thermal cycles between two temperatures, $400{ }^{\circ} \mathrm{C}$ and $900{ }^{\circ} \mathrm{C}$. Fine calibrations were performed on the thermal expansion of specimens with temperatures. A zero strain was applied at the mid-temperature of $650{ }^{\circ} \mathrm{C}$ before starting the TMF cycling. In a cycle, specimens were strained at $900{ }^{\circ} \mathrm{C}$ in the compression stage, unloaded, cooled to $400{ }^{\circ} \mathrm{C}$ in the tension stage, and then strained in the opposite direction to produce a completely reversed strain cycle. A hold time, ranging from 10 min. to 10 hours, was introduced at the maximum stress in compression for some of the TMF tests. The wave type of TMF was triangular and /or trapezoidal. The stress response and hysteresis loop were recorded at specified intervals. Figure 1 shows a schematic plot of an out-of-phase (OP) TMF cycling, in which, $\varepsilon_{\mathrm{t}}$ is total strain, $\mathrm{T}$ is temperature, $\mathrm{t}_{\mathrm{H}}$ is hold time in the compression stage. The total cycle period ranged from $6 \mathrm{~min}$. to 606 min., depending on the hold time at the maximum strain in compression.

Deformed specimens after TMF tests were sectioned parallel to the (100) plane for metallography and scanning electron microscopy (SEM, Philips XL30) characterization and comparison of microstructural changes while TMF was conducted. TEM specimens were prepared from the sections of TMF specimens, perpendicular to the longitudinal axis or along the $\{111\}$ planes of superalloy by mechanical grinding and subsequent electro-chemical polishing, and examined by using a microscope (Phillips CM200) operating at $200 \mathrm{kV}$.

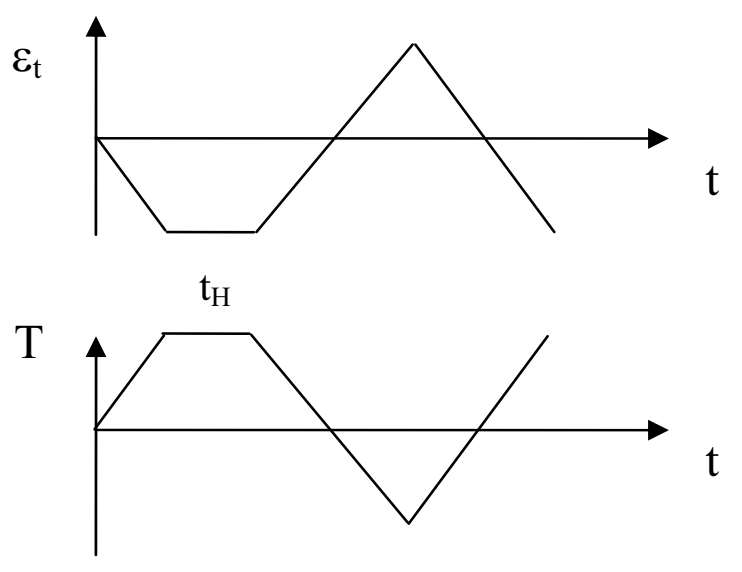

Figure 1. Schematic diagram of out-of-phase TMF cycling. 


\section{Results and Discussion}

Table II summarizes the TMF results. The plastic strain range $\varepsilon_{\mathrm{p}}$ was defined as the difference between the maximum and minimum plastic strain amplitudes at half cycles to failure. The plastic strain was calculated as $\varepsilon_{\mathrm{p}}=\varepsilon_{\mathrm{t}}-\sigma / \mathrm{M}(\mathrm{T})$, where $\sigma$ is the axial stress and $\mathrm{M}(\mathrm{T})$ is the elastic modulus.

Table II. TMF data, where $\varepsilon_{\mathrm{t}}$ is the total strain range, $\varepsilon_{\mathrm{e}}$ is the elastic strain, $\varepsilon_{\mathrm{e}}$ is the elastic strain, $\mathrm{N}$ is the cycle number, $\mathrm{N}_{\mathrm{f}}$ is the number of cycles to failure, $\sigma$ is the total stress amplitude, $\sigma_{\mathrm{t}}$ and $\sigma_{\mathrm{c}}$ are the maximum stresses in tension and in compression at half cycles to failure, $\mathrm{T}$ is the temperature range, and $t_{\mathrm{H}}$ is the hold time.

\begin{tabular}{|c|c|c|c|c|c|c|c|c|c|c|c|}
\hline \multirow[t]{2}{*}{ Type } & \multirow{2}{*}{$\begin{array}{c}\mathrm{T} \\
\left({ }^{\circ} \mathrm{C}\right)\end{array}$} & \multirow{2}{*}{$\begin{array}{l}\text { Cyclic } \\
\text { period }\end{array}$} & \multirow[t]{2}{*}{ Sample } & \multirow{2}{*}{$\begin{array}{c}\varepsilon_{\mathrm{t}} \\
(\%)\end{array}$} & \multirow{2}{*}{$\begin{array}{c}\mathrm{t}_{\mathrm{H}} \\
(\mathrm{min})\end{array}$} & \multirow[t]{2}{*}{$\mathrm{N}_{\mathrm{f}}$} & \multicolumn{5}{|c|}{$\mathrm{N}=\mathrm{N}_{\mathrm{f}} / 2,(\%, \mathrm{MPa})$} \\
\hline & & & & & & & $\varepsilon_{\mathrm{p}}$ & $\varepsilon_{\mathrm{e}}$ & $\sigma$ & $\sigma_{\mathrm{t}}$ & $\sigma_{\mathrm{c}}$ \\
\hline \multirow{13}{*}{$\begin{array}{l}\text { TMF } \\
\text { (out } \\
\text { of } \\
\text { phase) }\end{array}$} & \multirow{13}{*}{$\begin{array}{l}\leftrightarrow \\
900\end{array}$} & \multirow{13}{*}{$\begin{array}{l}6 \mathrm{~min} / \\
\text { cycle }\end{array}$} & \multirow{6}{*}{$\begin{array}{l}\text { TMS } \\
-75\end{array}$} & 0.97 & 0 & 5355 & 0.00 & 0.97 & 958 & 595 & 364 \\
\hline & & & & 0.99 & 60 & 311 & 0.06 & 0.93 & 1034 & 718 & 316 \\
\hline & & & & 1.28 & 0 & 985 & 0.00 & 1.28 & 1322 & 878 & -443 \\
\hline & & & & 1.28 & 10 & 158 & 0.13 & 1.15 & 1300 & 843 & -457 \\
\hline & & & & 1.31 & 60 & 48 & 0.19 & 1.12 & 1326 & 768 & -558 \\
\hline & & & & 1.28 & 600 & 22 & - & - & - & - & - \\
\hline & & & \multirow{7}{*}{$\begin{array}{c}\text { TMS } \\
-82+\end{array}$} & 1.01 & 0 & 1994 & 0.00 & 1.01 & 1143 & 761 & -382 \\
\hline & & & & 1.24 & 0 & 710 & 0.00 & 1.24 & 1361 & 928 & -433 \\
\hline & & & & 1.28 & 0 & 450 & - & - & - & - & - \\
\hline & & & & 1.27 & 10 & 308 & 0.03 & 1.24 & 1391 & 956 & -435 \\
\hline & & & & 1.29 & 60 & 70 & 0.09 & 1.20 & 1364 & 891 & -473 \\
\hline & & & & 1.28 & 60 & 86 & - & - & - & - & - \\
\hline & & & & 1.28 & 600 & 29 & 0.23 & 1.05 & 1470 & 957 & -513 \\
\hline
\end{tabular}

As seen from Table II, the introduction of the hold time led to a drastic reduction in the lifetime of TMF but to a different extent. Although the TMS-82+ has an inferior TMF property with $\mathrm{t}_{\mathrm{H}}=0$, it shows a remarkably better normalized rupture life than TMS-75 with $t_{H} \neq 0$ in Figure 2.

The curves of the variation in the maximum stresses under tension $\left(\sigma_{\mathrm{t}}\right)$ and compression $\left(\sigma_{\mathrm{c}}\right)$ during the TMF cycle are shown in Figure 3. Generally the variations in the stress vs. cycle during TMF are similar for the two superalloys. The total stress level of TMS-82+ is higher than that of TMS-75. The tensile stress of TMS- $82+$ at $400{ }^{\circ} \mathrm{C}$, in particular, is apparently higher than that of TMS-75 at $t_{\mathrm{H}} \neq 0$. On the other hand, the tensile ductility of
TMS-82+ at $400{ }^{\circ} \mathrm{C}$ is smaller than that of TMS-75. The elongations are $5.5 \%$ for TMS-82+ and $6.8 \%$ for TMS-75, respectively. This is because $\mathrm{Re}$ is an alloying element to harden the $\gamma$ phase, while the addition of refractory elements instead of Re in the TMS- $82+$ produced a stronger $\gamma$ ' phase. This may imply that a high strength at the low temperature in the tension stage, e.g., $400{ }^{\circ} \mathrm{C}$ in the present study, is an advantage for achieving a high TMF performance.

The above implication is confirmed by testing the relationship between the cycles to failure and yield stress, as shown in Figure 4, where data are collected at NIMS and MHI from a few superalloys. It can be concluded that the cycles to failure become longer with 
the increase of yield stress of SC superalloys ranging from $10 \mathrm{~min}$. to 10 hours in hold time.

Stress relaxation usually occurs at the compression stage during the hold period of an OP TMF. The sharp change in stress at the compression stage indicates stress relaxation during the hold period, which has been demonstrated to be important in the TMF of superalloys $[2,3]$. The relationship between cycles to failure and relaxation stress of the first cycle at $900{ }^{\circ} \mathrm{C}$ in the compression stage is shown in Figure 5. This suggests that cycles to failure tend to become shorter as the relaxation stress increases with the hold time, and the TMS-82+ has a smaller relaxation stress than the TMS-75. From results shown in Figures 4 and 5, it appears that there is no a strong correlation between cycles to

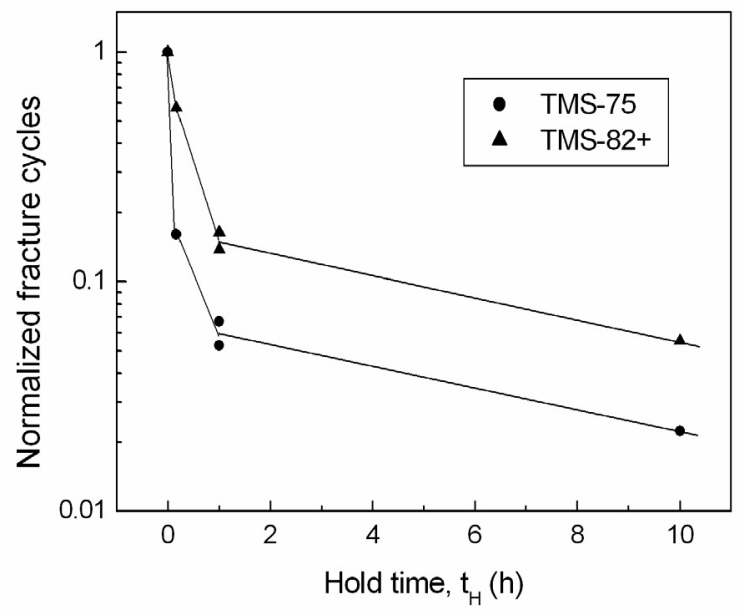

Figure 2. Normalized fracture life of the TMS-75 and TMS-82+.

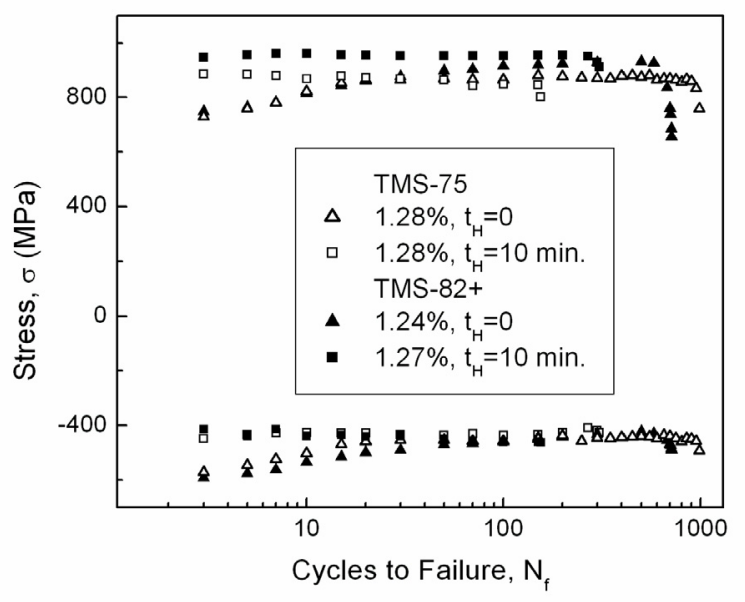

Figure 3. Cyclic softening /hardening curves during TMF cycling.

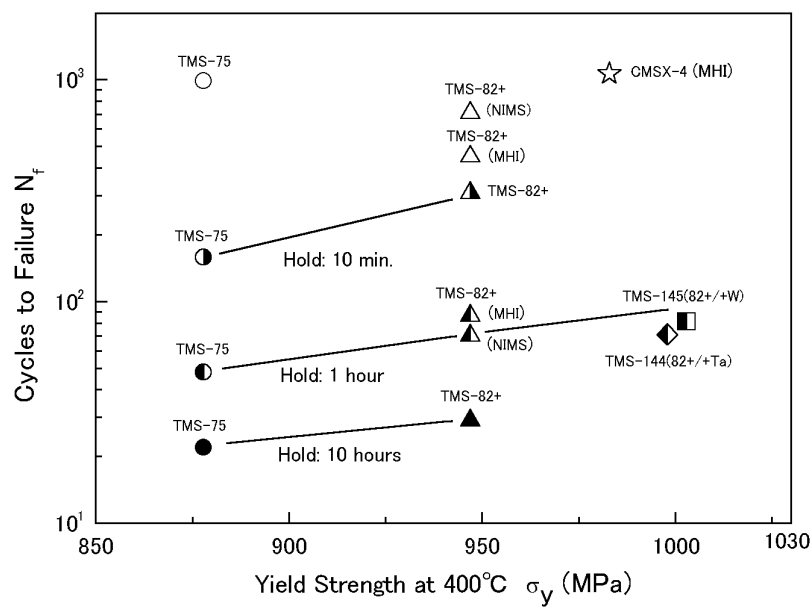

Figure 4. Cycles to failure vs. yield stress at $400{ }^{\circ} \mathrm{C}$; Open denotations represent the case of $\mathrm{t}_{\mathrm{H}}=0$.

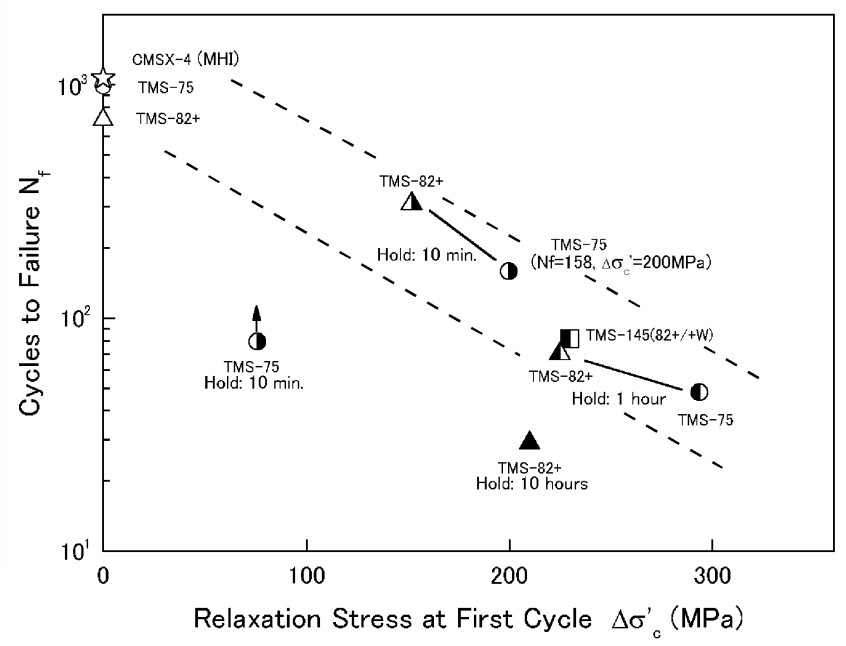

Figure 5. Cycles to failure vs. relaxation stress at first cycle.

failure or yield stress of SC superalloys with $t_{\mathrm{H}}=0$, although experimental data are limited.

The variation of the strain-stress hysteresis loop of TMS-75 and TMS-82+ was different. Typical loops for TMS-75 (Figure 6a) and TMS-82+ (Figure 6b), which were recorded at half cycles to failure under identical testing conditions, are shown in Figure 6. The yielding in the tension phase is caused by a transition from elastic strain to plastic strain due to a stress relaxation [2, 3]. It can be seen that the TMS-82+ has higher stress relaxation resistance in the compression stage than the TMS-75 under identical testing conditions. A higher stress relaxation resistance corresponds to a smaller plastic strain gained in the tension stage and a longer TMF rupture life. This result implies that a higher 
stress relaxation resistance at $900{ }^{\circ} \mathrm{C}$ would be advantageous to achieve a small plastic deformation in tension, and thus a good property in the case of TMF with the hold time.
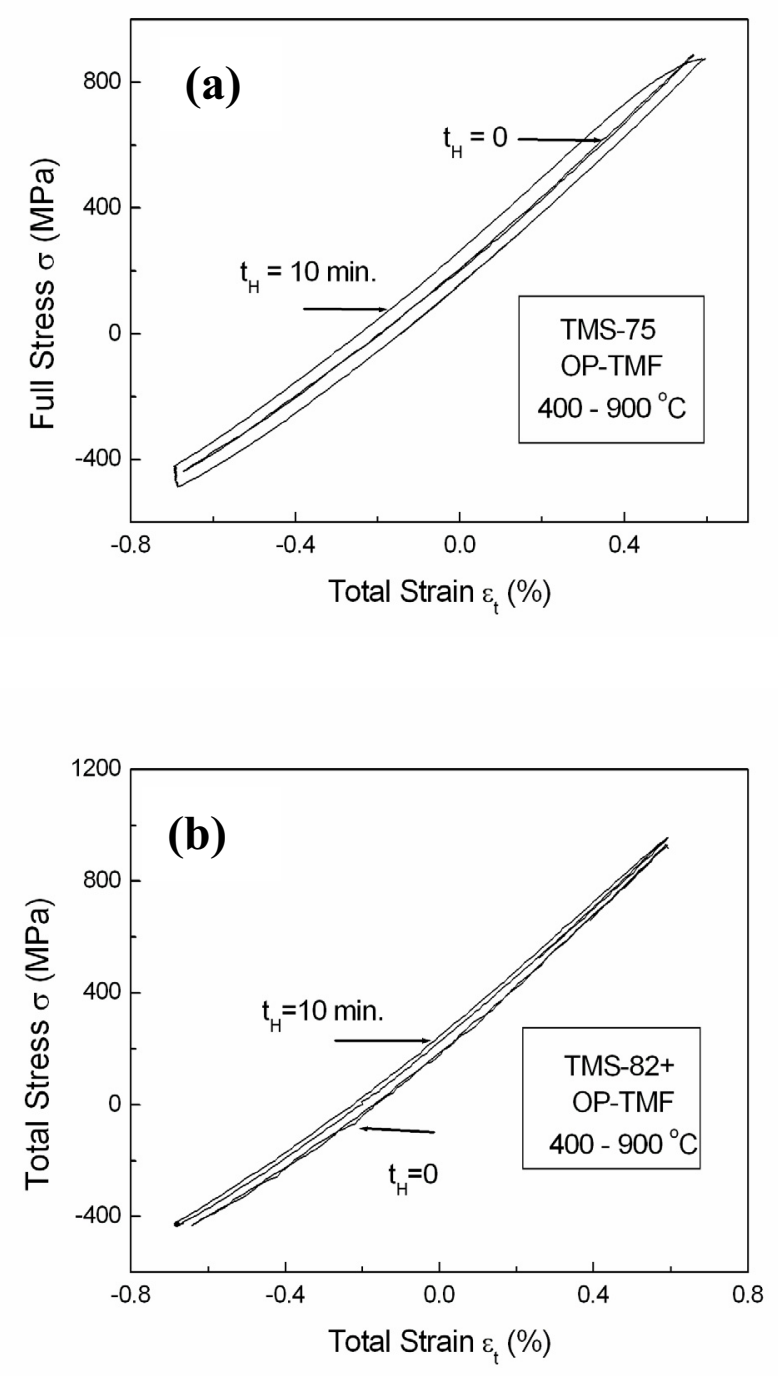

Figure 6. Stress relaxation behaviors of (a) TMS-75 and (b)

TMS- $82+$.

Microstructural observations by metallography and SEM indicated that a higher density of slip bands presented in TMS-75 (Figure 7a); on the other hand rare slip bands were found in the TMS-82+ (Figure 7b). The difference between the two alloys in the $\gamma / \gamma^{\prime}$ structure is shown in Figure 8. After rupture, no remarkable rafts were found in the TMS-75, but an incipient rafted structure parallel to the loading stress axis occurred in TMS-82+. This is because that the lower content of Re and lager negative mismatch were beneficial to the rafting in the compression stage of the TMS-82+. For all the rupture specimens, crack propagation nucleated at the external surface or inner pores and propagated predominantly along the direction perpendicularly to the loading stress axis. The rafts formed in TMS-82+ hindered crack propagation, which may explain the longer rupture life of the TMS- $82+$ in the case of $t_{\mathrm{H}} \neq 0$.
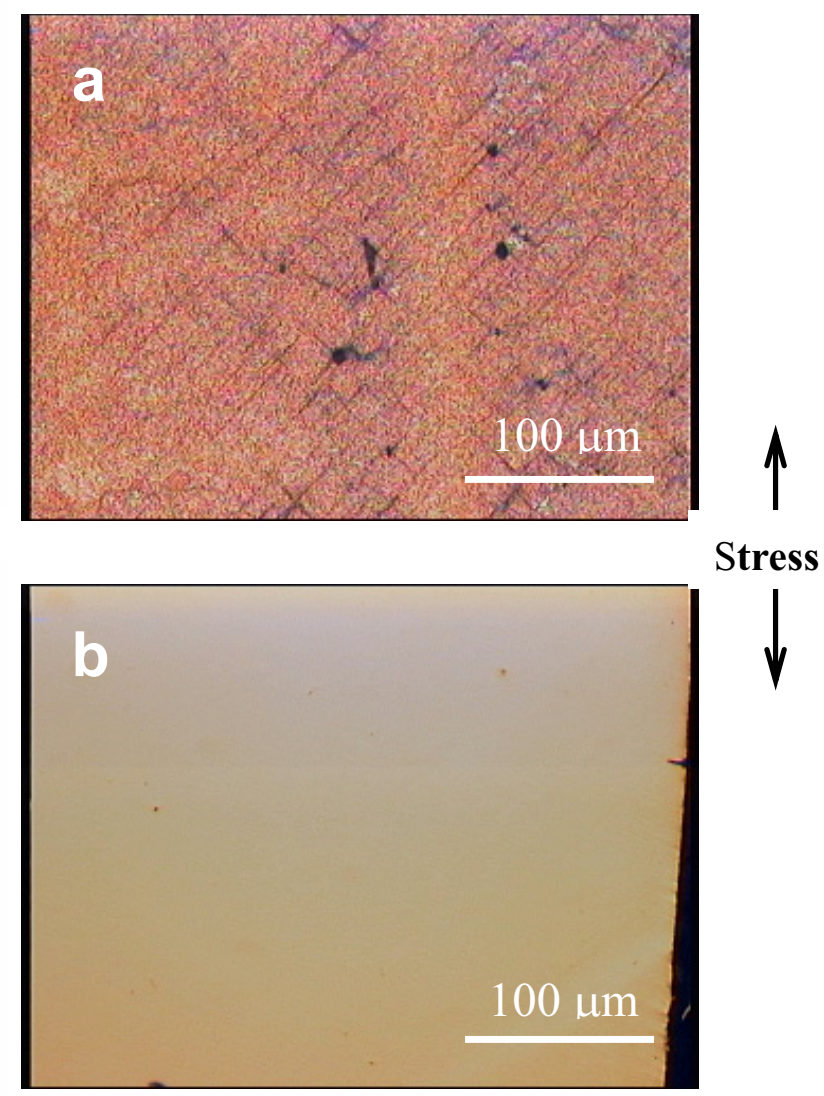

Figure 7. Light micrographs of (a) TMS-75; $\varepsilon_{\mathrm{t}}=1.31 \%, \mathrm{t}_{\mathrm{H}}=1 \mathrm{hr}$ and (b) TMS- $82+; \varepsilon_{\mathrm{t}}=1.24 \%, \mathrm{t}_{\mathrm{H}}=1 \mathrm{hr}$.

Defect structures of TMS-82+ and TMS-75 were investigated by TEM. In general, the dislocation density was increased with the fatigue cycles in both superalloys. In addition to the dislocations with the Burgers vector of $\mathrm{a} / 2<110>$ in the matrices, many stacking faults (SFs) were observed in the $\gamma^{\prime}$ precipitates (Figure 9). Inspections on the SFs in the two superalloys indicated that the formation of SFs resulted from the disassociation of single matrix dislocations confirming the previous conclusion [2-4]. Therefore, the formation of SFs in both alloys is expressed in equation (1).

$$
\mathrm{a} / 2[\overline{10} 01]=\mathrm{a} / 3[\overline{2} 11]+(\operatorname{SISF} / \mathrm{SESF})+\mathrm{a} / 6[1 \overline{2} 1]
$$



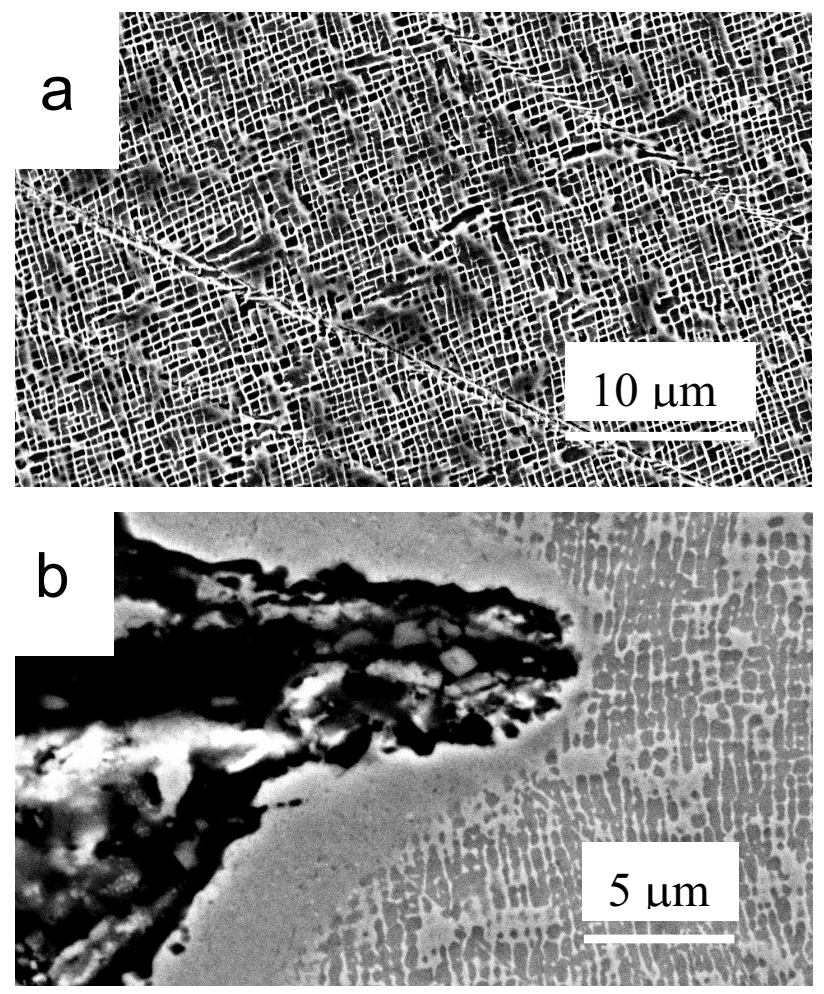

Figure 8. Scanning electron micrographs of (a) TMS-75; $\varepsilon_{\mathrm{t}}=1.31 \%, \mathrm{t}_{\mathrm{H}}=1 \mathrm{hr}$ and (b) TMS-82+; $\varepsilon_{\mathrm{t}}=1.24 \%, \mathrm{t}_{\mathrm{H}}=1 \mathrm{hr}$

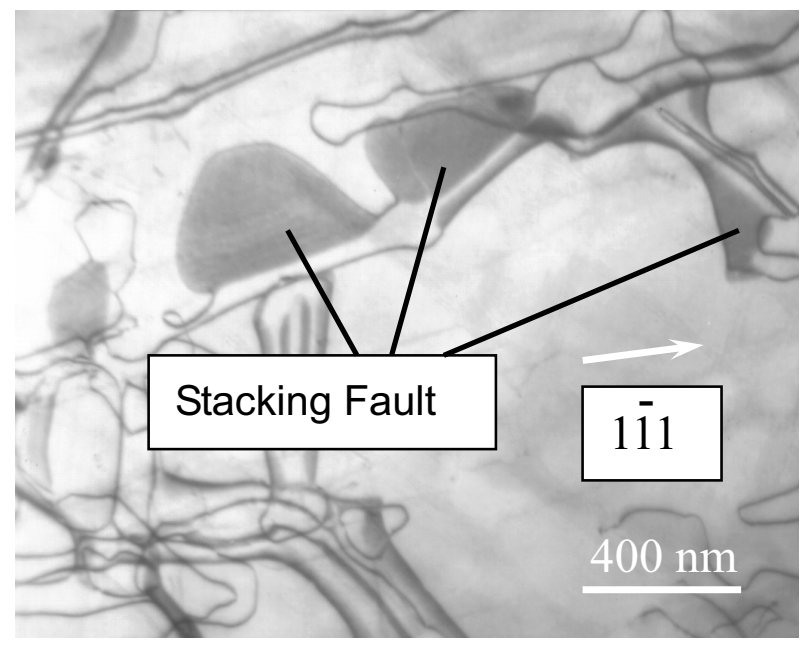

Figure 9. TEM photograph of a fatigued specimen of the TMS-75 tested under a condition of $\varepsilon_{\mathrm{t}}=1.28 \%$ and $\mathrm{t}_{\mathrm{H}}=10 \mathrm{~min}$.

A superlattice intrinsic/extrinsic stacking fault (SISF/SESF) was generated by the former partial shearing the $\gamma^{\prime}$ precipitate. Note that a few SFs are associated with a single matrix dislocation supporting equation (1). This characterization of the stacking faults concerned here is consistent with reports [7-9].

To clarify the effect of the chemical composition on the TMF behavior, we measured the chemical compositions of $\gamma$ and $\gamma$ ' phases in TMS-75 by electron probe X-ray micro-analyzer (EPMA), as shown in Figure 10. Most elements prefer to partition into the $\gamma$ phase because $\mathrm{Ni}_{3} \mathrm{Al}$ is a stable intermetallic compound with low energy. A similar trend has been found in other Ni-based superalloys [10]. Surprisingly it has been noted that the partitioning ratio of $\mathrm{Re}$ is approximately 9, while only $\mathrm{Al}$ and $\mathrm{Ta}$ tend to partition into the $\gamma^{\prime}$ phase. Therefore, the $\gamma$ ' phase was stronger in TMS-82+ because other refractory elements compensated for the loss of Re in TMS-82+. Finally, the overall strength of TMS-82+ was higher at $400{ }^{\circ} \mathrm{C}$ and $900{ }^{\circ} \mathrm{C}$, because the temperatures are relatively low and hence shearing of the $\gamma^{\prime}$ phase occurred during TMF.

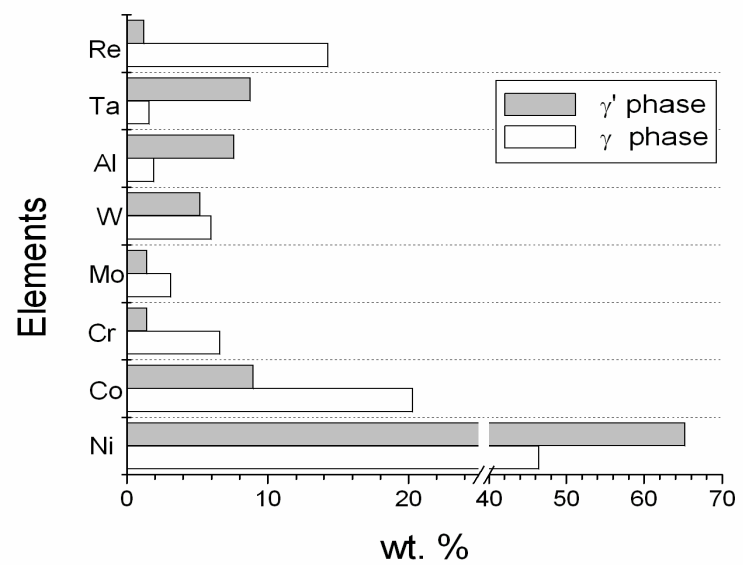

Figure 10. Chemical compositions of $\gamma$ and $\gamma^{\prime}$ phases in the TMS-75.

\section{Conclusions}

A comparative study of two Ni-based single-crystal superalloys was performed to investigated the thermal-mechanical fatigue properties. TMS-75 and TMS-82+, which were developed at NIMS, are third- and second-generation SC superalloys respectively. They had about $60 \%$ of $\gamma^{\prime}$ volume fractions but 
with different chemical compositions. Comparison between the two superalloys revealed the following:

(1) Although the TMF property of TMS-82+ was poor without a hold time, it exhibited a better TMF property than that of TMS-75 for TMF with a hold time.

(2) TMS-82+ showed higher tensile strength at $400{ }^{\circ} \mathrm{C}$ and higher stress relaxation resistance at $900{ }^{\circ} \mathrm{C}$ than TMS-75, which led to a smaller plastic deformation in tension and a longer rupture life in TMS-82+.

(3) A relatively smaller number of slip bands were observed in TMS-82+ than in TMS-75 under identical testing conditions, and a light rafted $\gamma / \gamma^{\prime}$ structure was observed in TMS-82+ for TMF with a hold time.

(4) The same deformation mechanism occurred in the two superalloys. The previous results concerning the mechanism of shearing the $\gamma^{\prime}$ precipitate by a single matrix dislocation were confirmed.

(5) Designing SC superalloys with excellent TMF properties, higher yield strength at low temperature and higher stress relaxation resistance at high temperature would be very effective.

TMS-82+, with its high phase stability, excellent high temperature creep strength and good TMF properties, is promising to be a substitute for the commercial second- and third-generation SC superalloys for the application in gas turbine engines.

\section{Acknowledgements}

Authors acknowledge greatly Dr. T. Murakumo and Dr. J.X. Zhang at NIMS, and Mr. K. Tsuagoshi and Mr. Y. kadoya at Mitsubishi Heavy Industries, Ltd., for their participation in helpful discussion.

\section{References}

1. T. Hino, T. Kobayashi, Y. Koizumi, H. Harada, and T. Tamagata: Superalloys 2000, ed. T.M. Pollock et al., 2000, p. 729-736

2. H.Zhou, H. Harada, Y. Ro, Y. Koizumi, T. Kobayashi and I. Okada, David L. Davidson symposium on Fatigue, 2002 (Seattle, WA: TMS Annual Meeting, 203-215.

3. H.Zhou, H.Harada, Y.Ro, T.Kobayashi and Y.Koizumi: Mat.Sci. Tech., 19 (2003), 847-852.

4. H.Zhou, I. Okada, Y. Ro, H. Harada, Y. Koizumi and T. Kobayashi, Metall. Mater. Trans. A, (2004), in press.

5. S. Kraft, R. Zauter and H. Mughrabi, Fatigue Fract. Eng. Mater. Struct., 16 (1993), 237-253.

6. F. Liu, S.H. Ai, Y.C. Wang, H. Zhang, and Z.G. Wang: Internat. J. Fatigue, 24 (2002), 841-846.

7. A.J. Huis in't Veld, G. Boom, P.M. Bronsveld, and J.T.M. de Hosson, Scripta Metall., 19 (1985), 1123-1128.

8. M. Condat and B. Decamps, Scripta Metall., 21 (1987), 607-612

9. P. Caron, T. Khan, and P. Veyssiere, Phil.Mag. A, 57 (1988), $859-875$

10. H. Harada and H. Murakami, Springer Series in Materials Science, Vol. 34, Ed. T. Saito, Springer-Verlag Berlin Heidelberg ,1999, Vol. 34, p. 39-70. 
